\title{
News from ASH 2019
}

\author{
Eberhard Gunsilius
}

Received: 9 June 2020 / Accepted: 17 June 2020

(c) Springer-Verlag GmbH Austria, part of Springer Nature 2020

The 61st ASH (American Society of Hematology) annual meeting and exposition was held in Orlando (FL, USA), December 7-10, 2019, with more than 25,000 attendees from more than 115 countries and almost 4900 featured abstracts. The constantly growing information overload at such "mega-meetings" does not always make it easy to keep an overview and separate the wheat from the chaff. I am happy and grateful that specialists with proven preclinical and clinical expertise in their field have agreed to do this job for us. In this issue of $M E M O$, selected highlights from the ASH meeting 2019 regarding chronic lymphocytic leukemia, aggressive B-cell lymphomas, multiple myeloma, and chronic myeloid leukemia are summarized by these experts. The latest developments in chimeric antigen receptor (CAR)T-cell therapy, also a main topic at ASH 2019, have been covered in the March issue of this journal [1].

Dr. Bohn and Dr. Wolf [2] summarize important clinical trials in the first-line treatment of chronic lymphocytic leukemia (B-CLL) that were presented at the meeting, illuminating the switch from nonspecific cytotoxic treatments in the past to nowadays highly specific and "chemo-free" strategies targeting malignant B-cells using tyrosine kinase inhibitors, and also address the lessons that still have to be learned.

The field of aggressive B-cell lymphomas is covered by Dr. Schmitt [3]. He discusses strategies for molecular subclassification of DLBCL, explains the data from trials using modern $\mathrm{T}$-cell based treatments and summarizes the good and less good news from clinical trials that implemented an immunomodulating drug (lenalidomide) or tyrosine kinase inhibitor

\section{E. Gunsilius ( $\bowtie)$}

Medical University Innsbruck,

Anichstraße 35, 6020 Innsbruck, Austria

eberhard.gunsilius@i-med.ac.at (ibrutinib) into the standard immunochemotherapy regimen R-CHOP. Clinically meaningful and directly implementable in our daily work is the reduction of the number of R-CHOP cycles in younger patients with stage I/II DLBCL without bulky disease and other risk factors to 4 cycles if an interim PET after 3 cycles is negative without loss of long-term disease control.

One of the most successful stories in the last one and a half decades that is still ongoing is the treatment of patients with multiple myeloma. Dr. Ludwig [4] highlights important clinical trials presented at the meeting as well as data on PET imaging, treatment of myeloma bone disease and clinical studies implementing novel and promising treatment approaches.

Despite tremendous and actually paradigmatic achievements in the treatment of chronic myeloid leukemia (the slightly older ones remember allogeneic bone marrow transplantation as the first-line treatment for younger patients with a significant treatment-related mortality and morbidity, now replaced by taking pills in all patients), there are still open questions in the management of this disease. How to improve further the number of patients that can be put "off-treatment" after achieving a deep molecular response? What is the best approach for patients failing first-line treatment and what strategy fits best for those in blast crisis? These questions are covered in the summary of the ASH highlights from Dr. Petzer [5].

The knowledge conveyed in these overviews has been gained through the voluntary willingness of patients and physicians to participate in clinical trials and preclinical studies. Including patients in academic concepts is always expandable and should be prioritized to keep up with the increasingly rapid development of new compounds that must be tested in carefully designed trials with appropriate patient numbers to generate robust data that can also be 


\section{editorial}

transferred in the future without hesitation into our daily patient care. I hope this issue of MEMO offers you valuable updates for routine clinical practice for the purpose of "lifelong learning" and also stimulates you for fruitful discussions on clinical and experimental hematology.

Conflict of interest E. Gunsilius declares that he has no competing interests.

\section{References}

1. Main Topic "CAR-TCells". memo 2020;13(1):27-54.

2. Bohn J-P, Wolf D. Fine-tuning front-line therapy in chronic lymphocytic leukemia. News from ASH 2019. memo. 2020. https://doi.org/10.1007/s12254-020-00615-y.

3. Schmitt CA. ASH highlights 2019: "aggressive B-cell lymphoma”. memo. 2020. https://doi.org/10.1007/s12254020-00619-8.
4. Ludwig H. Highlights of ASH 2019-multiple myeloma. memo. 2020. https://doi.org/10.1007/s12254-020-00612-

5. Petzer AL. Myeloid diseases-Chronic Myeloid Leukemia (CML) - report from ASH 2019 on new developments. memo 2020. https://doi.org/10.1007/s12254-020-00616-

Publisher's Note Springer Nature remains neutral with regard to jurisdictional claims in published maps and institutional affiliations.

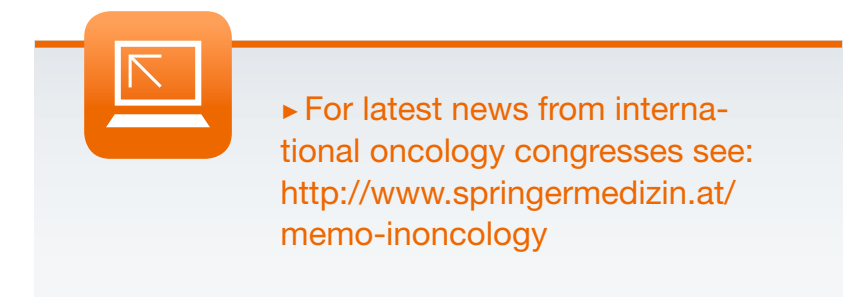

